\title{
Pure Electric Vehicle Power-train Parameters Matching based on Vehicle Performance
}

\author{
Meilan Zhou, Liping Zhao, Yu Zhang, Zhaoming Gao and Rongjie Pei \\ Harbin University of Science and Technology College of Electrical and \\ Electronics Engineering,Harbin, China \\ Zhoumeilan001@163.com
}

\begin{abstract}
In order to alleviate the problem of pollution caused by emissions of conventional vehicles, strengthen the development and promotion of pure electric vehicle, electric vehicle performance was studied. According to the vehicle dynamic performance index, the parameters of pure electric vehicle power system were calculated and matched, among them, the drive motor and battery parameters were matched reasonably mainly. Simulation platform AVL-CRUISE was used to build the vehicle model based on the New European Driving Cycle (NEDC) and the Chinese typical urban cycle, in addition, analyzed its dynamic performance and economic performance. The simulation results are very close to theoretical results, which verify the matching of power system parameters is reasonable. The results show that, pure electric vehicle consumes $15.29 \mathrm{kwh}$ one hundred kilometers when operating $N E D C$, and $12.48 \mathrm{kwh}$ one hundred kilometers when Chinese typical urban cycle, the driving range of electric vehicle is $110 \mathrm{~km}$.
\end{abstract}

Keywords: Pure electric vehicle; Power system; Parameter matching; Working conditions; Power consumption

\section{Introduction}

Pure electric vehicle has incomparable advantage over conventional vehicle in terms of energy conservation, emissions reduction and ensuring oil supply security, etc., which has attracted wide attention of automobile manufacturers and governments [1]. Foreign famous automobile company attaches great importance to the development of pure electric vehicles, the world's developed countries do not hesitate to invest in research to promote the development of electric vehicle. Although China started late in this regard, the government concentrates every force on the development of electric vehicle, and parts of the technology already surpass the world advanced level.

Since dynamic system is the core of automotive vehicle, it determines the performance of the vehicle. Strict calculation and parameter matching is required in the process of research about development of power system, in order to satisfy the demand of vehicle dynamic performance. Christoph Weissinger developed a concept for a pure electric vehicle, he tried to develop the vehicle from scratch and optimize the drive train using a structured approach, estimated energy storage on the basis of the New European Driving Cycle (NEDC) besides [2]. Kang Huang proposed a design method for pure electric vehicles driving motor, considered the vehicle power performance according to the requirements of road conditions in Chinese cities [3].

In this paper, dynamic system parameters like the motor speed torque characteristics, the efficiency curve and parameters of battery, etc, were reasonably matched in order to improve the performance of electric vehicle. Not only based on the NEDC cycle, but also established the Chinese typical urban road condition according to the characteristics of urban road in China, then compared two kinds of working conditions, and analyzed the vehicle dynamic performance and economic performance. 


\section{Parameters of Pure Electric Vehicle Matching}

Pure electric vehicle power-train system mainly includes the battery, drive motor, reducer, gearbox, clutch, etc. Among them, drive motor and battery is the core part. In order to increase the transmission efficiency and reduce the mechanical transmission device, the traditional automobile clutch can be omitted in the power transmission system of electric vehicle arrangement. The power system of pure electric vehicle designed in this paper contained motor, battery, mechanical driving device and control system. The structure diagram of automobile power system as is shown in Figure 1.

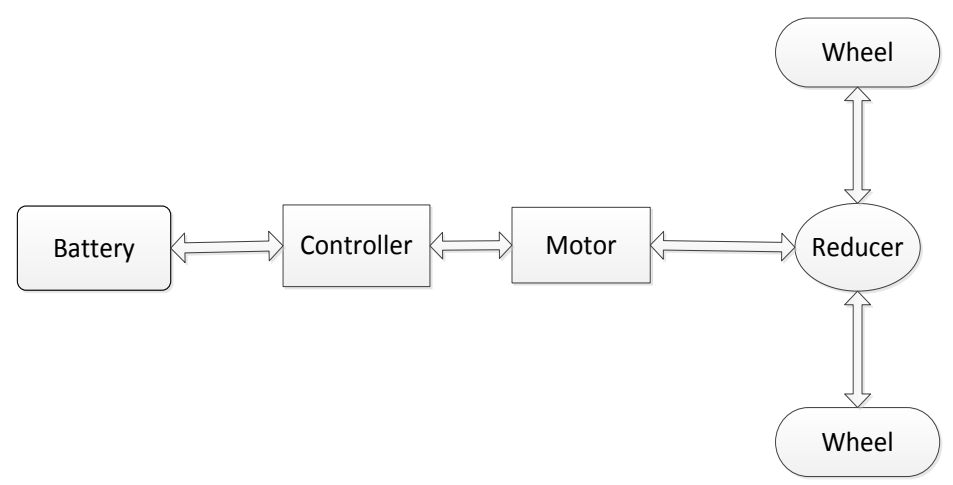

Figure 1. Pure Electric Vehicle Power System Structure

In this paper, the drive motor and power battery parameters were matched mainly according to the design requirements of vehicle. The vehicle basic parameters as is shown in Table 1.

Table 1. Vehicle Basis Parameter

\begin{tabular}{|c|c|c|c|}
\hline $\begin{array}{c}\text { CURB Weight } \\
(\mathrm{kg})\end{array}$ & 1050 & $\begin{array}{c}\text { Frontal Area } \\
\left(\mathrm{m}^{2}\right)\end{array}$ & 1.97 \\
\hline $\begin{array}{c}\text { Gross Weight } \\
(\mathrm{kg})\end{array}$ & 1350 & $\begin{array}{c}\text { Transmission } \\
\text { Efficiency }\end{array}$ & 0.9 \\
\hline $\begin{array}{c}\text { Wheelbase } \\
(\mathrm{mm})\end{array}$ & 2467 & $\begin{array}{c}\text { Drag } \\
\text { Coefficient }\end{array}$ & 0.284 \\
\hline $\begin{array}{c}\text { Wheel Rolling } \\
\text { Radius (mm) }\end{array}$ & 279 & $\begin{array}{c}\text { Rolling } \\
\text { Resistance } \\
\text { Coefficient }\end{array}$ & 0.018 \\
\hline
\end{tabular}

Pure electric vehicle performance indicators as is shown in Table 2.

Table 2. Vehicle Performance Indicators

\begin{tabular}{|c|c|c|}
\hline \multirow{4}{*}{$\begin{array}{c}\text { Power } \\
\text { Performance }\end{array}$} & $\begin{array}{c}\text { Maximum Speed }(\mathrm{km} / \mathrm{h}) \\
(0 \sim 50 \mathrm{~km} / \mathrm{h}) \text { Acceleration Time } \\
(\mathrm{s})\end{array}$ & $\leq 10$ \\
\cline { 2 - 3 } & $\begin{array}{c}\text { Maximum Climbable Gradient } \\
(\%)\end{array}$ & $\geq 15$ \\
\hline Economy & Endurance Mileage $(\mathrm{km})$ & $\geq 100$ \\
\hline
\end{tabular}




\section{Matching Motor Parameters}

\subsection{The Motor Rated Power and Peak Power Matching}

The selection of drive motor rated speed and maximum speed should conform to the requirements of the torque speed characteristic of the motor. When the car starts, the motor speed is low and works in constant torque state, as long as speed is higher than the rated speed, it works in constant power state, as shown in Figure 2.

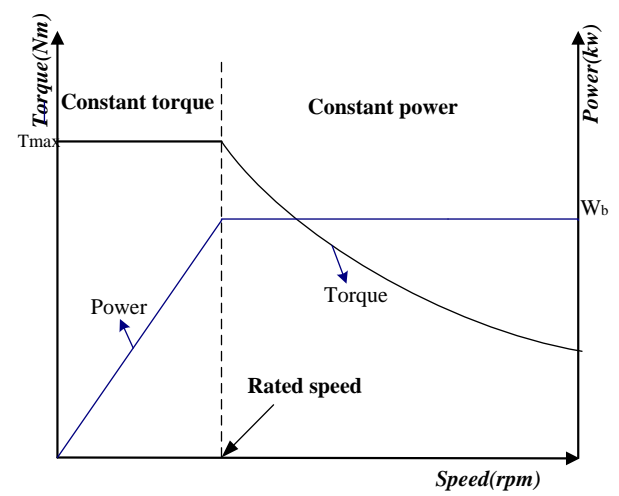

Figure 2. Drive Motor Torque Characteristics

The peak power of the motor is generally determined by pure electric vehicle maximum speed, acceleration time and maximum gradient.

First, according to the maximum speed:

$$
P_{\max 1}=\frac{v_{\text {max }}}{3600 \eta_{T}} \times\left(m g f+\frac{C_{d} \cdot A \cdot v^{2}{ }_{\text {max }}}{21.15}\right)
$$

Where $\eta_{T}$ is the transmission coefficient efficiency; $m$ is vehicle weight; $f$ is rolling resistance coefficient; $\mathrm{C}_{\mathrm{d}}$ is drag coefficient; $\mathrm{A}$ is frontal area; $\mathrm{v}_{\max }$ is maximum speed. Calculated $\mathrm{P}_{\max 1}=22.9 \mathrm{KW}$, integer $23 \mathrm{KW}$.

Secondly, according to the maximum gradient:

$$
p_{\text {max } 2}=\frac{v}{3600 \eta_{T}} \times\left(m g f \cos \alpha_{\text {max }}+m g \sin \alpha_{\text {max }}+\frac{C_{d} \cdot A \cdot v^{2}}{21.15}\right)
$$

Where $\alpha_{\max }$ is maximum climbable gradient; $\mathrm{v}$ is the speed when maximum climbable gradient. The result is $21 \mathrm{KW}$ by calculation.

Finally, according to the acceleration time:

$$
P_{\max 3}=\frac{1}{3600 \cdot t \cdot \eta_{T}}\left(\delta m \cdot \frac{v_{m}{ }^{2}}{2 \sqrt{t}}+m g f \cdot \frac{v_{m}}{1.5}+\frac{C_{d} \cdot A \cdot v_{m}{ }^{3}}{21.15 \times 2.5} \cdot t\right)
$$

Where, $\mathrm{t}$ is the acceleration time; $\delta$ is rotating mass conversion coefficient (1.04 $\sim 1.08), \mathrm{v}_{\mathrm{m}}$ is accelerating terminal velocity. Calculated $\mathrm{P}_{\max 3}=35 \mathrm{kw}$.

Maximum power of the motor $\mathrm{P}_{\max }$ must satisfy the condition $\mathrm{P}_{\max } \geq \max \left\{\mathrm{P}_{\max 1}\right.$, $\left.\mathrm{P}_{\max 2}, \mathrm{P}_{\max 3}\right\}$. The peak power of the motor should be $40 \mathrm{kw}$ according to the results.

The rated power of electric vehicles is $P_{e}=\frac{P_{\max }}{\lambda}, \lambda$ is overload coefficient of the motor, then $\mathrm{P}_{\mathrm{e}}$ ranged from 14 to $40 \mathrm{kw}$. 


\subsection{Selection of Motor Rated Speed and the Highest Speed}

The greater the motor power, the better maximum acceleration and climbing of the electric vehicle, but the volume and quality of motor will increase correspondingly, what is worse, the motor will be difficult to maintain high efficiency, then energy utilization ratio will reduce. The highest speed of the motor has a great influence on the cost and manufacturing technology of the motor. Speed at $6000 \mathrm{r} / \mathrm{min}$ above requires high precision, high cost and has large noise at run time [4], so the highest motor speed selected is lower than $6000 \mathrm{r} / \mathrm{min}$. The rated speed of the motor is determined by the motor constant power coefficient $\beta$, which is generally 2 to 4 , so the rated speed of motor was $1500 \sim 3000 \mathrm{r} / \mathrm{min}$.

Combined with the analysis results above, the motor parameters as is shown in Table 3.

Table 3. Electric Machine Basis Parameter

\begin{tabular}{|c|c|}
\hline Rated Power $(\mathrm{kW})$ & 30 \\
\hline Peak Power(kW) & 40 \\
\hline Rated Speed(r/min) & 1500 \\
\hline Maximum Speed $(\mathrm{r} / \mathrm{min})$ & 6000 \\
\hline
\end{tabular}

\section{Matching Power Battery Parameters}

The power source of the pure electric vehicles is battery, therefore, the selection of battery parameters must meet the demand of endurance mileage requirements and maximum power of vehicle driving. Lithium battery is selected as the power source for electric vehicles due to its long life and mass energy density [5-8].

The nominal voltage of lithium iron phosphate batteries on the market is $3.2 \mathrm{~V}$, then the battery voltage level is $U=3.2 \times 100=320 \mathrm{v}$.

$$
P=\frac{v_{1}}{3600 \eta_{T}} \times\left(m g f+\frac{C_{d} A v_{1}^{2}}{21.15}\right) \quad P_{m}=\frac{p}{\eta_{m}} \quad W_{\text {road }}=P_{m} t=\frac{P_{m} S}{v_{1}}
$$

Where $\mathrm{P}$ is the power required for the automobile constant speed, $\mathrm{S}$ is endurance mileage, $\mathrm{W}_{\text {road }}$ is the energy needed for mileage $\mathrm{S}, \mathrm{P}_{\mathrm{m}}$ is the input power of the motor controller, $\eta_{\mathrm{m}}$ is the motor and motor controller assembly efficiency. The energy of the battery pack $\mathrm{W}$ should be greater than $\mathrm{W}_{\text {road, }}$, a formula $W \xi_{\text {soc }}=W_{\text {road }}, \xi_{\text {soc }}$ took 0.7 . The energy of the battery pack calculated is $18 \mathrm{KWh}$.

$$
C=\frac{1000 P_{\mathrm{m}} S}{U_{b} \xi_{s o c} v_{1}}
$$

, $\mathrm{C}$ is the battery capacity meet the mileage, $\mathrm{U}_{\mathrm{b}}$ is the average working voltage of the battery, get $\mathrm{C} 57 \mathrm{Ah}$, the combination of power battery is 3 in parallel and 100 series.

\section{The Simulation of Pure Electric Vehicle and Analysis}

Recently simulation method of electric vehicle mainly includes facing-forward simulation and facing-backward simulation, both of them have their own merits and shortcomings. As the facing-backward simulation cannot be used for dynamic simulation of actual driving state, and the facing-forward simulation calculates more accurately, the facing-forward simulation is more preferred. CRUISE is a facingforward software developed by AVL company studying on vehicle power performance, fuel economy, emission performance and braking performance [9-10]. 
The vehicle dynamic system includes battery, motor, clutch, gearbox, reducer and wheels, while clutch and gearbox were not added to the dynamic system of pure electric vehicle in this paper. The vehicle model was built with Cruise, as shown in Figure 3.

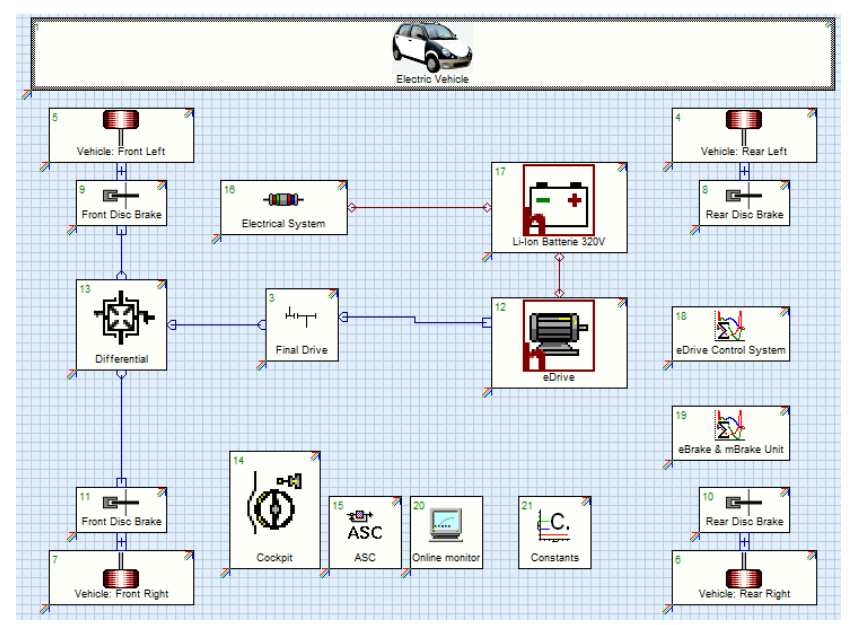

Figure 3. Pure Electric Vehicle Model

\subsection{Cycle Run Analysis}

Pure electric vehicles are mainly driven on urban road, so established NEDC and the Chinese typical urban cycle as operating conditions, as shown in Figure 4 (a), 4(b). Respectively for the NEDC cycle and Chinese typical urban cycle. You can see the normal speed in NEDC cycle is at $40 \sim 60 \mathrm{~km} / \mathrm{h}$, and Chinese typical urban cycle's normal speed converges on $20 \sim 40 \mathrm{~m} / \mathrm{h}$.

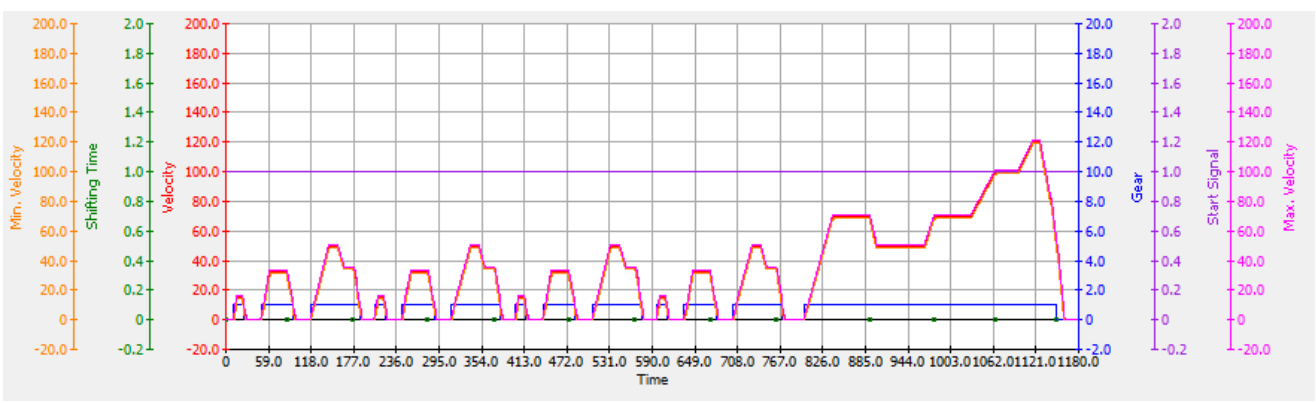

Figure 4(a). NEDC Cycle

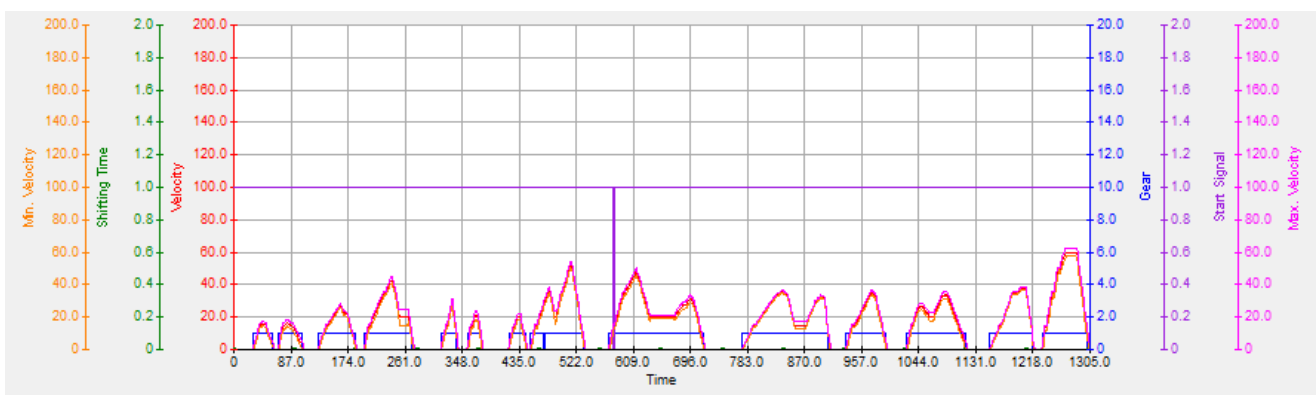

Figure 4(b). Chinese Typical Urban Cycle

The motor's characteristics for NEDC cycle and the Chinese typical urban cycle is as the following figures, the motor work efficiency respectively focus on 
$75 \% \sim 89 \%$ and $76 \% \sim 86.7 \%$, the maximum output power of the motor in the cycles is $39 \mathrm{KW}$ and $14.7 \mathrm{~kW}$, no more than $40 \mathrm{~kW}$, the supreme power of the motor.

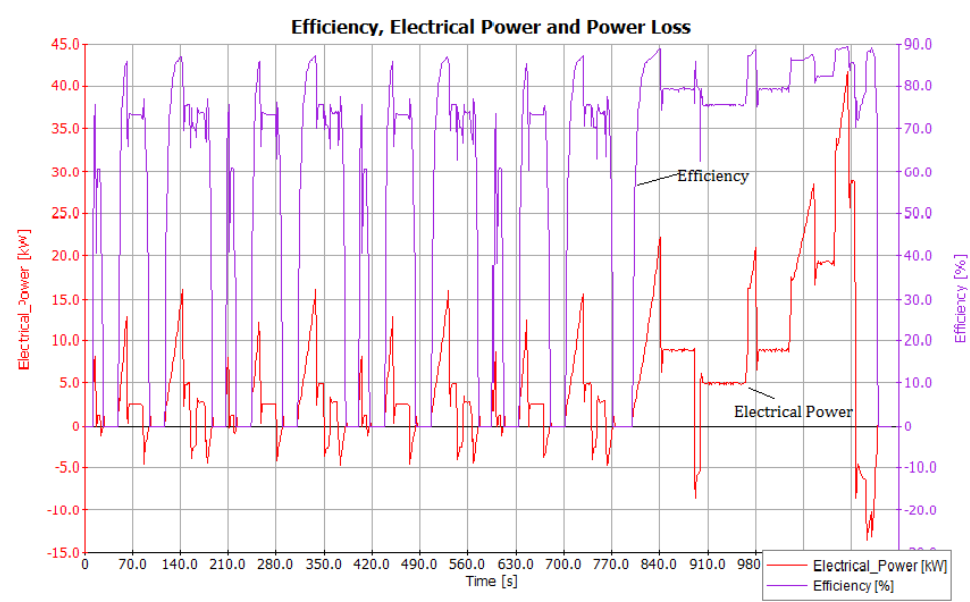

Figure 5(a). Motor Output Efficiency and Output Power Curves of NEDC Cycle

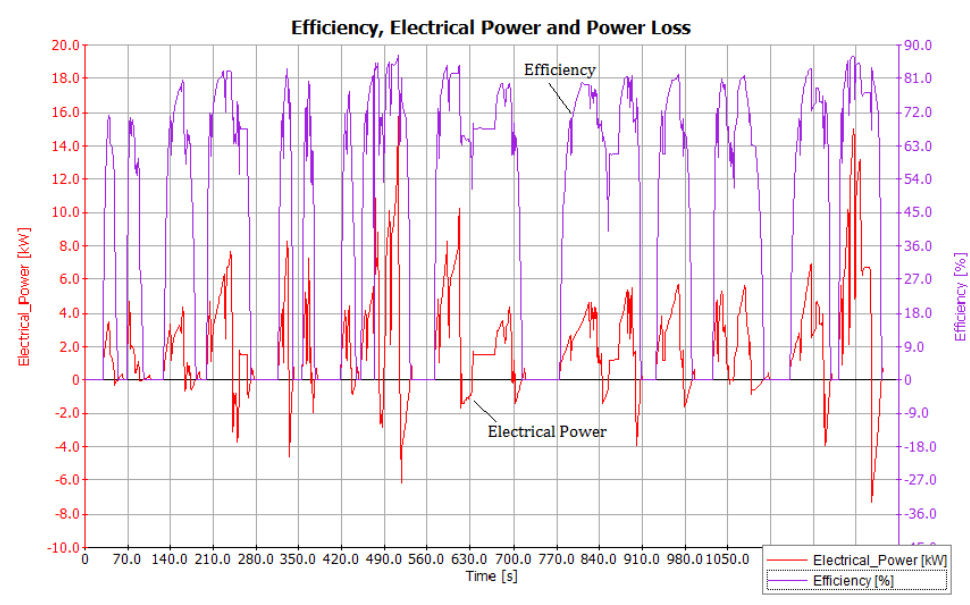

Figure 5(b). Motor Output Efficiency and Output Power Curves of Chinese Typical Urban Cycle

\subsection{Pure Electric Vehicle Dynamic Performance Analysis}

\section{(1) Climbing Performance Simulation}

The maximum gradient of pure electric vehicles CRUISE calculated when traveling at a certain speed is shown in Figure 6. The requirement for gradient under the speed 30 $\mathrm{km} / \mathrm{h}$ in the design is $15 \%$ at least, as can be seen from Figure 6 , the climbing gradient is $20.7 \%$, over $15 \%$, met the design requirements. 


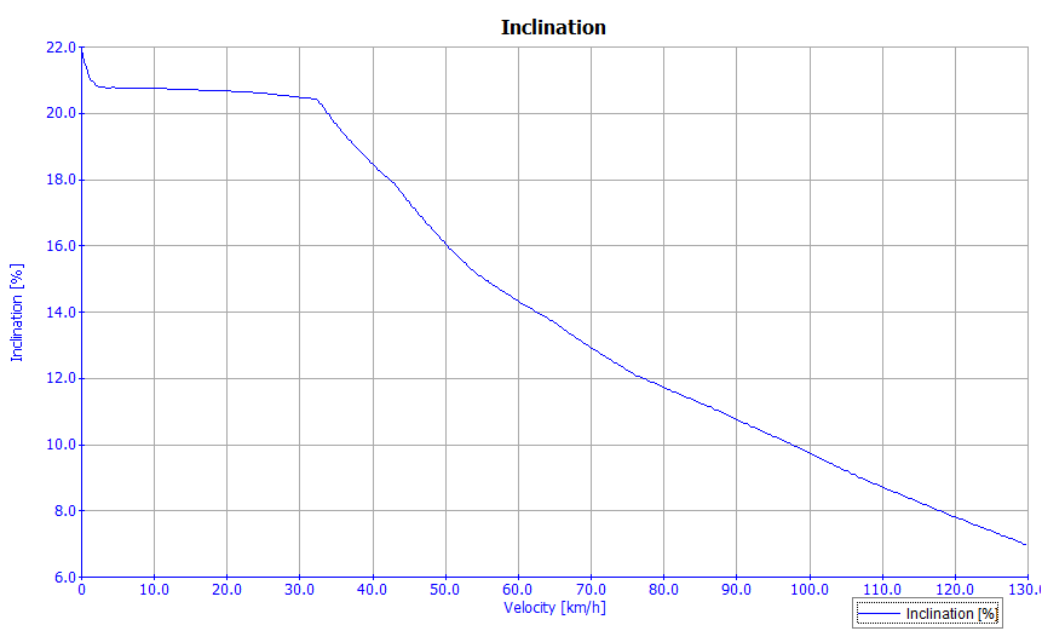

Figure 6. Gradient under Different Speed of the Vehicle

\section{(2) The Acceleration Performance Calculation}

The accelerating time of auto is an important index in measuring system performance, the shorter acceleration time, the better the performance of automobile. Figure 7 is the simulation results of acceleration time for pure electric vehicle with CRUISE, in which can be seen $0 \sim 50 \mathrm{~km} / \mathrm{h}$ acceleration time is $5.7 \mathrm{~s}$, in less than $10 \mathrm{~s}$ and met the acceleration index of pure electric vehicle designed.

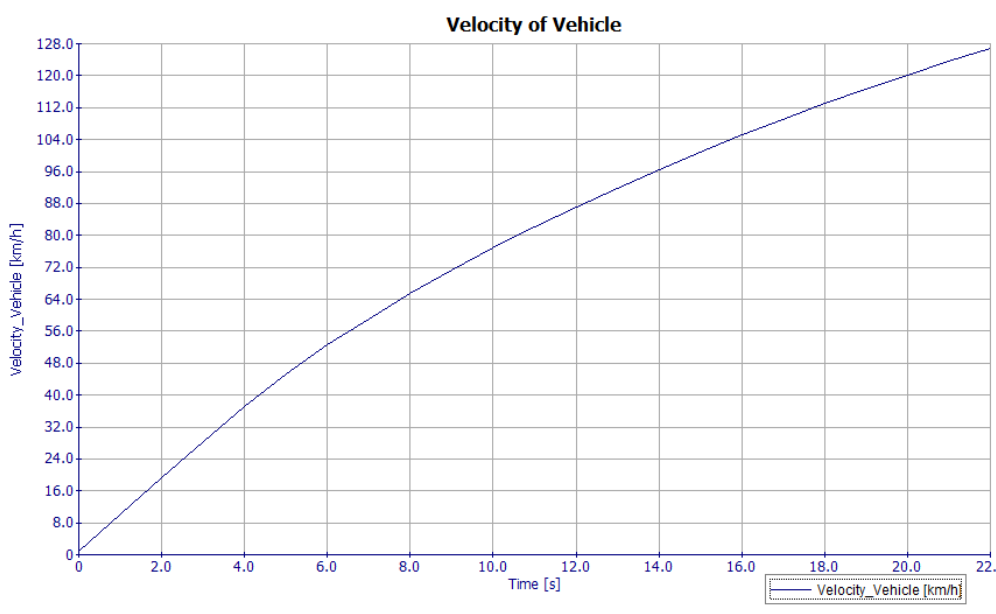

Figure 7. Acceleration Time Curve

\section{(3) The Maximum Speed Simulation}

The maximum speed is the highest speed the car can reach on road, then the pure electric vehicle motor is generally in the constant power operation process. There is a

$$
\frac{3599.97 P_{e} \cdot r \cdot \eta}{v_{1}}=m g f+\frac{C_{D} A v_{\max }^{2}}{21.15}
$$

formula:

, the calculated maximum speed is about calculated result, as shown in Figure 8. 


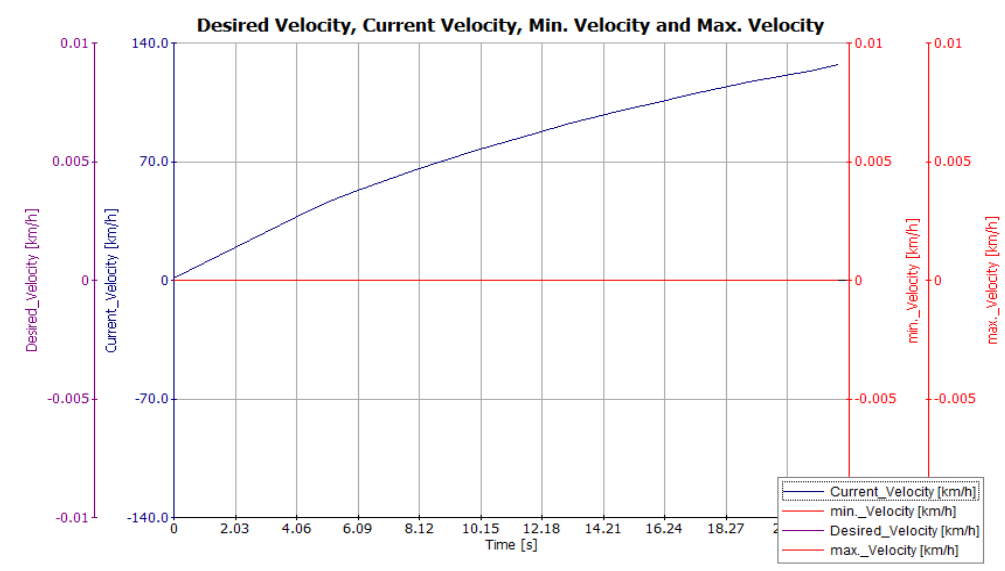

Figure 8. Vehicle Speed Curve

\subsection{Economic Performance Analysis of Pure Electric Vehicles}

The electrical consumption in 100 kilometers for pure electric vehicle designed in the NEDC cycle is $15.29 \mathrm{kwh}$ through CRUISE software simulation, while in Chinese typical urban cycle the number is $12.48 \mathrm{kwh}$. The simulation curves of power consumption are shown in Figure 9 (a), 9 (b).

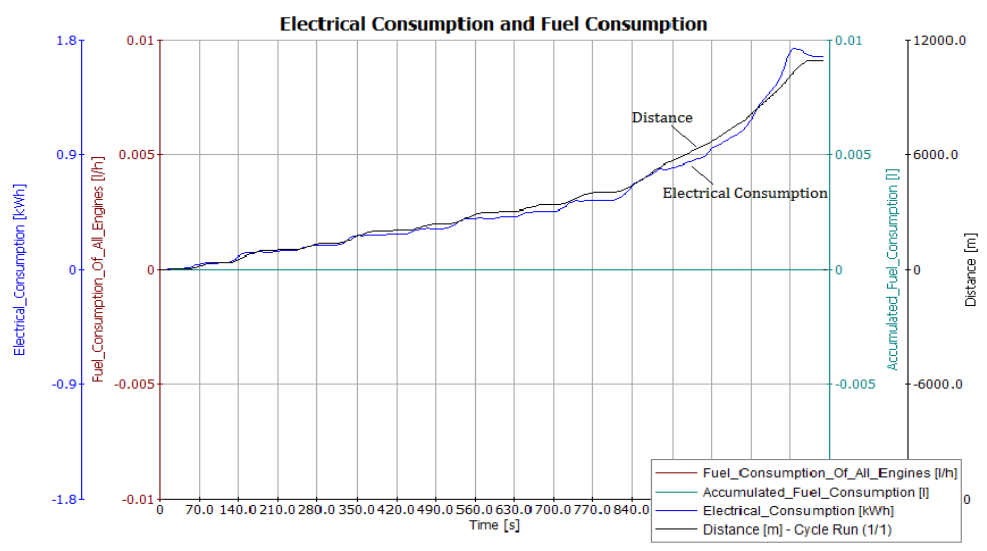

Figure 9(a). Pure Electric Car Power Consumption Curve in NEDC Cycle

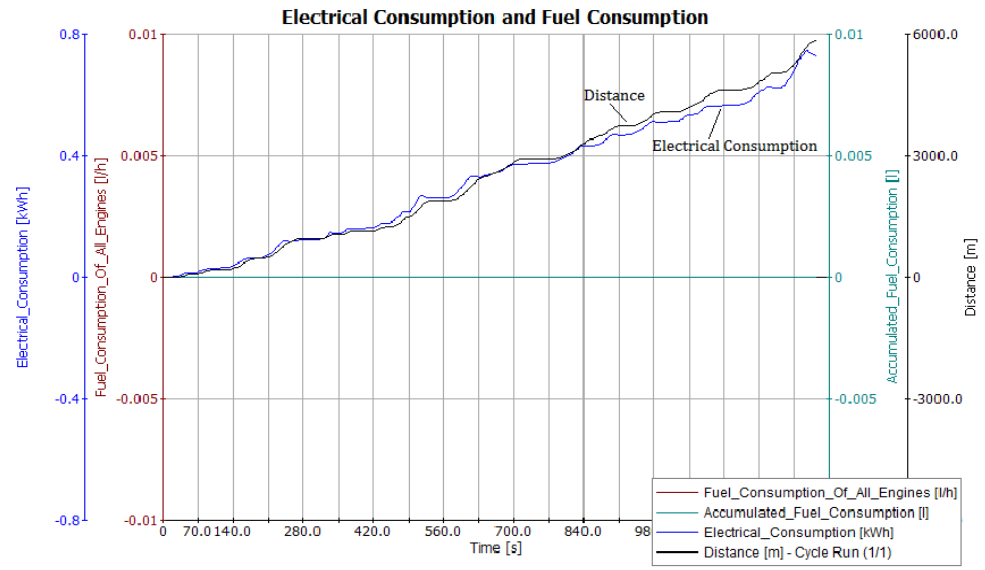

Figure 9(b). Power Consumption Curve of Pure Electric Vehicles in Chinese Typical Urban Cycle 
As there is no estimate for mileage in the simulation of CRUISE software, used the following method. Established constant speed driving cycle in CRUISE. Assuming the vehicle drives at $60 \mathrm{~km} / \mathrm{h}$ constant speed on road, as shown in Figure 10, ignored the impact of external factors and environment, set the depth of battery discharge $70 \%$. As can be seen from the Figure 10, battery SOC decreased with increasing mileage. Selected the SOC value $30 \%$ for the corresponding mileage as driving range of pure electric vehicle. Mileage which can be seen from the figure is $110 \mathrm{~km}$, achieves the performance index of the mileage for at least $100 \mathrm{~km}$.

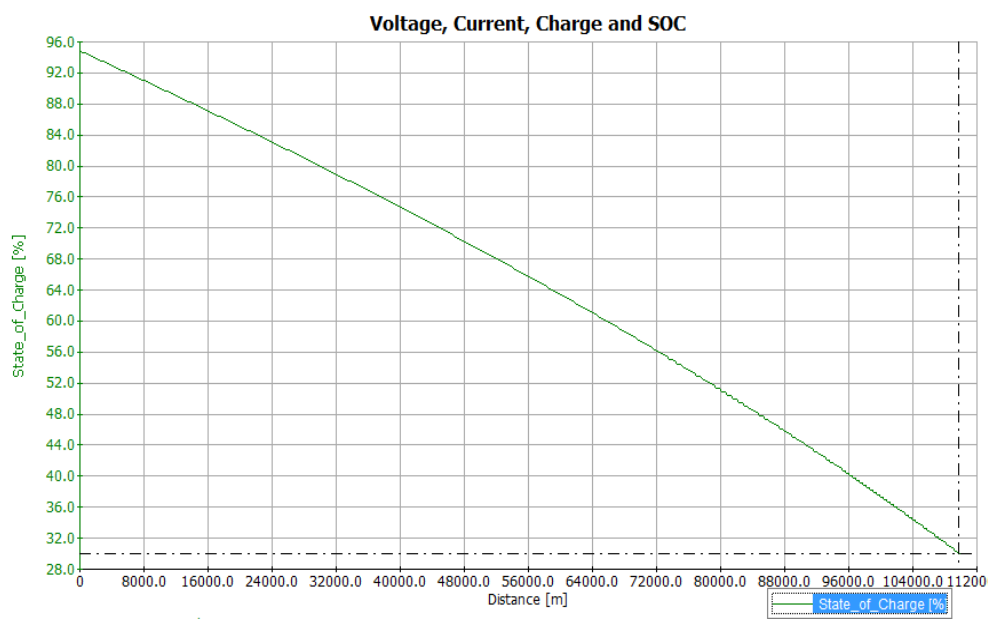

Figure 10. Constant Speed $60 \mathrm{~km} / \mathrm{h}$ Curve in SOC

\section{Conclusion}

Studied on the dynamic system of pure electric vehicles based on dynamic performance and economic performance, parameters of driving motor and power battery were determined by calculation combined with the vehicle simulation software CRUISE. As simulation results met the design requirements with high precision, it verified the rationality of pure electric automobile power system parameters matching. The pure electric vehicle designed has good dynamic performance and economic performance. The result shows that the electrical consumption in 100 kilometers for pure electric vehicle designed in the NEDC cycle is $15.29 \mathrm{kwh}$ through CRUISE software simulation, while in Chinese typical urban cycle the number is $12.48 \mathrm{kwh}$, endurance mileage reaches $110 \mathrm{~km}$. This paper provides methods and reference for manufacturers about the development of the automobile power system.

\section{Acknowledgements}

This work was financially supported by Heilongjiang Natural Science Foundation (E201302).

\section{References}

[1] J. N. Yu, G. H. Liang, J. Wang and D. Li, "Pure electric vehicle driving system parameter matching in motor higher efficiency interval", Systems and Informatics (ICSAI), International Conference, (2012)

[2] C. Weissinger, D. Buecherl and H. Herzog, "Conceptual design of a pure electric vehicle", Vehicle Power and Propulsion Conference (VPPC), IEEE , (2010).

[3] K. Huang and D. Zhu, "Study on Driving Motor of Pure Electric Vehicles Based on Urban Road Conditions", Communication Systems and Network Technologies (CSNT), International Conference, (2013). 
[4] Y. J. Feng, K. Yang, S. D. Huang, L. Gao and W. J. Zhang, "Research of interior permanent magnet brushless DC motor for electric vehicles", Electrical Machines and Systems (ICEMS), International Conference, (2013)

[5] R. J. Wai, S. J. Jhung and J. J. Liaw, "Intelligent optimal energy management system for hybrid power sources including fuel cell and battery", Power Electronics, IEEE Transactions, vol.28, no.7, (2013), pp.3231-3244.

[6] Y. Jiang and Z. P. Jiang, "Robust adaptive dynamic programming with an application to power systems", Neural Networks and Learning Systems, IEEE Transactions, vol.24, no.7, (2013), pp.1150-1156

[7] J. Cao and A. Emadi, "A New Battery/Ultra Capacitor Hybrid Energy Storage System for Electric,Hybrid, and Plug-In Hybrid Electric Vehicles", IEEE transactions on power electronics, vol.27, no.1, (2012), pp.122-132.

[8] J. Y. Du, M. G. Ouyang and H. W. Wang, "Battery electric vehicle parameters design targeting to costbenefit objective", Vehicle Power and Propulsion Conference (VPPC), IEEE, (2012).

[9] B. H. Wang and Y. G. Luo, "AVL cruise-based modeling and simulation of EQ6110 hybrid electric public bus", Computer Application and System Modeling (ICCASM), International Conference, (2010).

[10] M. L. Zhou, R. X. Liu, N. N. Ding, X. G. Wu and W. Q. Zhu, "Economy analysis of extended range electric vehicle in different control strategies", Measurement, Information and Control (ICMIC), International Conference, (2013). 